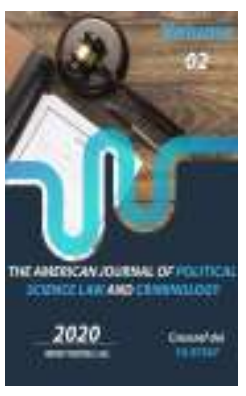

\title{
The Importance Of Forensic Examination In Criminal Exposure
}

\author{
Abdumutal Karimovich Zakurlaev \\ Associate Professor At The Department "Criminal Law" Specialized Branch Of Tashkent State \\ University Of Law, Doctor Of Sciences In Law, Uzbekistan
}

Journal Website:

http://usajournalshub.c

om/index,php/tajpslc

Copyright: Original

content from this work

may be used under the

terms of the creative

commons attributes

4.0 licence.

\section{ABSTRACT}

The article deals with the issues of examination and its types and significance, which are assigned during the preliminary investigation and inquiry.

\section{KEYWORDS}

Scene, investigator, forensic expert, forensic laboratory, physical evidence, biological materials, evidence value in resolving the guilt.

\section{INTRODUCTION}

The main purpose of the ongoing reforms in the Republic of Uzbekistan, which fully covers all spheres of society, is to protect the rights and freedoms of citizens, ensure peace and stability in society maintain harmony between nations and citizens. Speaking of reforms, one of the most important directions of democratic renewal of our country at this stage is the gradual democratization and liberalization of the judiciary, aimed at strengthening the rule of law and the rule of law, reliable protection of individual rights and interests. In this regard, the head of state said that "the people should serve the people, not government agencies" [1] consistency is important. 


\section{METHODS}

In our country, the further improvement and strengthening of the rule of law means the need to reform the judiciary and ensure the protection of human rights. One of the key factors in achieving the above goal is to ensure legitimacy in society. Forensic science plays an important role in addressing issues that require specialized knowledge in the field of science, technology, culture and profession in addressing the challenges facing law enforcement agencies and courts. In their activities, they should make full use of the opportunities of forensic examination in the process of rapid disclosure of various types of crimes, impartial investigation and trial, as well as dispute resolution. Because forensic science is the main procedural tool for determining the true state of affairs in a case based on specialized knowledge, it is an indisputable fact.

\section{RESULTS AND DISCUSSIONS}

This is especially important at a time when our country is experiencing a slight increase in the quality and quantity of crime, the emergence of new types. Effective detection and investigation of crimes requires the active work of law enforcement agencies to identify and expose the perpetrators, to obtain information relevant to the search and evidence. One of the means of gathering evidence and search information is to investigate the investigative actions, especially the urgent investigative action - the scene of the incident. The main tasks of crime scene investigation are to identify the circumstances of the incident, as well as to find, record, initially investigate and seize traces of the crime. Careful and consistent review of the scene of an incident, and ultimately an effective one, is the key to success in uncovering and investigating any crime.
In order to achieve a positive result in the examination of the scene of the incident, the persons conducting the examination must have in-depth theoretical knowledge and practical skills in working with different traces. The investigator conducting the examination, as well as the forensic expert involved in it, should be familiar with the classification of traces, the procedure for finding, initially inspecting and removing them, the types of traces and where they can be found (taking into account what happened). It is important to be able to use forensic tools, methods and techniques skillfully. This is necessary to ensure the ability to consistently search for traces at the scene of the incident, to determine the mechanism of the incident, to advance the hypotheses of the investigation, as well as to ask questions in a clearly justified manner when appointing forensic experts. It should be noted that in recent years, many courts, prosecutors, investigators and inquiry officers consider it the duty of a forensic expert to participate only in the examination. Of course, a forensic expert must assist the investigator. However, it may not be appropriate for the inquiry officer or investigator to attempt to impose on others the actions of working with traces. In addition, an on-site inspection consists of a direct recording and examination by the investigator of the crime scene, the traces and other objects present in it, in order to obtain factual information relevant to the case. The results of the criminal investigation show that in the absence of a forensic expert, traces are usually not found at all, or even if they are found, they are superficially described in the report, without taking into account the requirements of criminal procedure law, expertise and investigative practice.

It should also be noted that in some cases there is a superficial approach to the search for traces. That is, if any traces are found, the focus on the search for other traces is reduced, which 
reduces the likelihood of crime detection and leads to a significant poor quality of the evidence base [3, p.356] .Therefore, the material traces found at the scene, especially when working with common species, there is a need to pay special attention to the characteristics of finding, recording and removing them. The discovery of crimes committed in practice depends primarily on the detection of visible and invisible traces in the process of inspection of the scene [4, p.36]. They are traces that are visible and blurry or difficult to see. Special luminaries are used to detect these traces, as well as mechanical and chemical methods (e.g., invisible handprints on paper, or micro particles, fiber, and biological body separations (fat-sweat traces) found on objects left at the scene. The following measures should be taken to preserve the traces found at the scene: a) not to place persons here who may damage or destroy the traces; b) take measures to prevent accidental damage to the traces (the person performing the inspection should move in a predetermined direction, the objects should be carefully inspected, following the relevant recommendations); c) immediate recording of traces that may change or deteriorate under the influence of air temperature, wind, sunlight and precipitation, as well as traces found in perishable food products; d) marking the area or objects where traces were found at the scene of the incident so that participants in the inspection do not accidentally injure them (for example, the traces can be marked with chalk or digital signs can be placed near them); e) cover human or animal feet, vehicle wheel tracks with planks, plywood, boxes and other available materials (buckets, tubs, oilcloths, clothing, etc.) if precipitation is expected; sheds can also be formed on the molds; f) Covering traces of scattering materials (sandy soil) with plywood, a piece of cardboard, board or spraying reinforcing agents (6\% shellac solution in hairspray or alcohol) to prevent the wind from blowing. In this case, the flow of solution is directed upwards so that the fine droplets of the composition are absorbed into the trace. The spraying is continued until a welldistinguishable film is formed on the traces; $g$ ) installation of barriers around the tracks on the carriageway, prohibiting traffic and indicating detours; h) protection of traces found at the scene of the accident from exposure to strong chemical compounds and high temperatures that could lead to their deterioration.

Traces of substances are traces of liquid, pasty and scattering substances formed as a result of preparation, commission or concealment of a crime. These include traces of blood (dripping, splashing, leaking, spotted blood stains), traces of fuel, brake fluids, alkalis and so on. Trasological studies of such traces focus only on determining the mechanism of trace formation. Trace-perceptions are traces formed as a result of the interaction of two objects, in which the external structure of one object and other features are reflected in another object. Trace-perceptions are traces in the narrow sense of the word. Most of them are traces of people, unlocking devices, criminal weapons, vehicles, animals and so on.

It is in the narrow sense that traces (perceptions) are the main object of research in forensic trasology. Traces in the broadest sense can become the object of study of trasology when the problem of determining the mechanism of trace formation and conducting situological research, the situation at the scene, the elements of this situation and the relationship between them are considered in terms of movement, dynamics and development. In turn, traces or reflections can be classified on different grounds: 1 . According to the trace objects: - Anthroposcopic traces traces that directly reflect the properties of the human body and its parts (hands, feet, lips, 
teeth, fingers, palms, heels, etc.); Anthropomechanoscopic traces - traces that reflect the properties of the human body and its parts in clothing or footwear, or the properties of objects (prostheses, dentures, teeth) that replace parts of the human body and perform their functions to a certain extent. Briefly speaking, traces of biological significance are the traces of the highest evidentiary value and the highest indicators of identification. As an example, papillary traces at the scene are identified and examined by an expert and are not removed because they have been smeared for research. If this trace is treated with as a biological material, its chemical composition is preserved and copied, which allows confirm the identity of the person as a biological material when examined by human DNA examination. Then, if the inside of the glove used to hide the traces of the offender as an example of the situation is examined, it is possible to identify the sweat-oil separations that are the basis of the fingerprints. In turn, these distinctions allow the identification of an individual by human DNA examination [5].

In the most common type of pick pocketing, in practice, along with biological traces of fat, the widest part of the offender's clothing must be in contact with the victim's pockets, sweat and oil are released. These sweat-oil traces, of course, are absorbed into the pocket, but also allow micro-particles in the pocket to pass through most of the clothes. Assuming the same situation in the case of murder, it will be possible to determine the connection of microfibers and micro-particles, as well as to find traces through a logical connection, and then to appoint an expert study of the situation. At present, this type of examination of human DNA at the Republican Center for Forensic Examination named after $\mathrm{H}$. Suleymanova under the Ministry of Justice, along with effective research, makes a significant contribution to ensuring the inevitability of punishment for a crime and proving guilt.

\section{CONCLUSION}

In short, with the development of modern types of expertise, the opportunities for crime detection have expanded. In all of these opportunities, first of all, the court, prosecutor, investigator, inquiry officer and experts will be able to think logically, mentally restore the actions of the perpetrator and find traces of his actions in connection with the environment of the crime scene and recognize these traces as evidence in the future. That is, there is no unsolved crime, only the constant work of those responsible for the detection of the crime, the application of the theory and practice to the investigative activity through logical thinking, will pave the way for the eradication of crime.

\section{REFERENCES}

1. From the speech of the President of the Republic of Uzbekistan at the joint session of the Legislative Chamber of the Oliy Majlis and the Senate // October 6, 2018 Khalk suzi.

2. Kondratyeva I. Genetics to the rescue: DNA as evidence https://pravo.ru/process/view/145542/

3. Belkin R.S. Criminalistics of the problem, trends in the development of prospects. Moscow, 2015.

4. Pulatov Yu.S. Peculiarities of the tactics of searching for traces at the scene by the investigator and the investigator. Tashkent, 2015. IMPRESS MEDIA 36 p.

5. Levchenko U.V. Traces of a person of biological origin as an object of forensic research: Dissertation for obtaining the degree of Ph.D in the specialty 12.00.09. 